\title{
Health Risks, Race, and Adolescents' Use of School-Based Health Centers: Policy and Service Recommendations
}

\author{
Yolanda Anyon, MSW, PhD \\ Megan Moore, MSW, PhD \\ Elizabeth Horevitz, MSW, PhD \\ Kelly Whitaker, MPA \\ Susan Stone, MSW, PhD \\ John P. Shields, PhD
}

\section{Introduction}

School-based health centers (SBHCs) offering health and behavioral health services in educational settings are an increasingly popular strategy to improve adolescents' access to care, particularly in lowincome communities of color where youth experience social, economic, and geographic barriers to care that result in high rates of unmet behavioral and physical health needs. ${ }^{1}$ Recent studies of SBHCs in high school settings indicate that, relative to their proportion in the general school population, Black and Latino students tend to be overrepresented in these programs, whereas White and Asian youth are underrepresented. ${ }^{2,3}$ One possible explanation is that these patterns reflect differential need for services resulting from higher health risks (e.g., depression, substance use, asthma, or unprotected sexual activity) among Black and Latino youth because of their disadvantaged social location. Growing up in neighborhoods with concentrated poverty and exposure to racial discrimination is associated with a host of negative health and psychosocial outcomes in adolescence. ${ }^{4-7}$ In addition, limited availability and quality of health services in low-income communities of color, along with inadequate insurance

Address correspondence to Yolanda Anyon, MSW, PhD, Graduate School of Social Work, University of Denver, 2148 South High Street, Denver, CO 80208, USA. Phone: +1-415-7945859; Fax: +1-303-8712845; Email: yanyon@du.edu.

Megan Moore, MSW, PhD, School of Social Work, University of Washington, 4101 15th Avenue NE, Seattle, WA 98105 ,

USA. Email: mm99@uw.edu

Elizabeth Horevitz, MSW, PhD, School of Social Welfare, University of California, Berkeley,120 Haviland Hall, Berkeley, CA 94720, USA. Phone: +1-510-6424341; Fax: +1-510-6436126; Email: ehorevitz@berkeley.edu

Kelly Whitaker, MPA, ETR Associates, 251 Rhode Island St., Suite 204, San Francisco, CA 94103 USA. Phone: +1-4152520402; Fax: +1-415-2520443; Email: kellyw@etr.org

Susan Stone, MSW, PhD, School of Social Welfare, University of California, Berkeley, 120 Haviland Hall, Berkeley, CA 94720, USA. Phone: +1-510-6436662; Fax: +1-510-6436126; Email: sistone@berkeley.edu

John P. Shields, PhD, ETR Associates, 251 Rhode Island St., Suite 204, San Francisco, CA 94103, USA. Phone: +1-4152520402; Fax: +1-415-2520443; Email: johns@etr.org

Journal of Behavioral Health Services \& Research, 2002. 1-11. (c) 2002 National Council for Community Behavioral Healthcare. DOI 10.1007/s11414-013-9356-9 
coverage, create obstacles to accessing appropriate care; therefore, SBHCs aim to mitigate these barriers by making services more affordable and conveniently located..$^{8-12}$

However, it is unlikely that disparities in unmet need fully explain patterns of racial group differences in SBHC use. Previous research indicates that racial disparities in adolescents' use of community-based health and behavioral health services persist after controlling for need, severity, and a variety of caregiver and youth characteristics. ${ }^{12-19}$ The underrepresentation of Asian students in SBHCs also challenges the differential need explanation. Research has demonstrated that Asian youth experience racial discrimination and chronic stress related to poverty and acculturation and have even higher rates of unmet health and behavioral health needs than their Black or Latino peers. ${ }^{20-22}$ Many scholars have argued that Asian adolescents with health risks may be less likely to access formal services because of cultural stigma against extrafamilial help seeking. ${ }^{23}$ Although behavioral health treatment is stigmatized across all racial minority groups, negative attitudes towards formal service use and preferences to rely on friends and family during times of stress may be stronger for Asian youth and could offer more explanatory power in their case. ${ }^{24}$ Thus, students' utilization patterns may not only be shaped by unmet health-related needs but also by cultural and contextual processes that shape help seeking.

It is also likely that these cultural and contextual influences on service use operate differently depending on the setting in which care is provided. ${ }^{17,22}$ Yet previous research in this area has largely been conducted in community-based health systems or has not disaggregated findings by setting. There is a need for empirical studies focused on the unique and distinct organizational context of school systems, particularly in light of the tremendous growth of school-based behavioral health services in recent years. ${ }^{25}$ Racial group differences in SBHC access, where Black and Latino youth tend to be overrepresented, are striking in contrast to those observed in communitybased behavioral health-care systems, where these groups are consistently underserved. Such patterns may indicate that SBHCs are more responsive to the needs and help-seeking preferences of Black and Latino adolescents and have great potential to reduce long-standing access disparities for these populations. However, the underrepresentation of Asian students in SBHCs is puzzling in light of research, suggesting that these youths' health needs are not being met elsewhere. ${ }^{22}$

Instead of lower unmet need for services among Asian youth, the underrepresentation of Asian students in SBHCs may reflect the influence of the "model minority" myth, which stereotypes Asian youth as academically successful and problem-free, on school staff referral practices and provider outreach efforts. ${ }^{23}$ Likewise, the overrepresentation of Black and Latino youth could indicates the influence of negative stereotypes or the pathologizing of externalizing behaviors. ${ }^{26,27}$ In the case of SBHCs, students can self-refer to services, but like other school-based support programs, youth often access care after being referred by a teacher or other school staff member. ${ }^{26-31}$ In contrast, adolescents enter community-based services largely due to parental concern. ${ }^{28,30}$ Parents of adolescents and school staff members often have different views of student behavior and likely have different motivations for encouraging youth to seek health or behavioral health services. Therefore, racial disparities in community-based versus school-based services are likely different, potentially driven by distinct causal mechanisms. ${ }^{28,31}$ The unique dynamics of help seeking in educational settings indicate that there is a need for exploration of patterns of SBHC utilization by health risk and by racial group, with a specific focus on Asian youth.

\section{Theoretical Framework}

Given the complexity of factors that contribute to racial disparities in health risks and access to care, a multilevel social-ecological framework is required to understand patterns of SBHC service use by race. This study draws on the cultural and contextual framework of Cauce et al. ${ }^{31}$ for adolescent help seeking that recognizes factors at multiple levels that contribute to disparities in unmet need and service access (see Fig. 1). From this perspective, racial group differences in service use reflect multilevel familial, 
Figure 1

Theoretical framework for adolescent help seeking and service use ${ }^{31}$

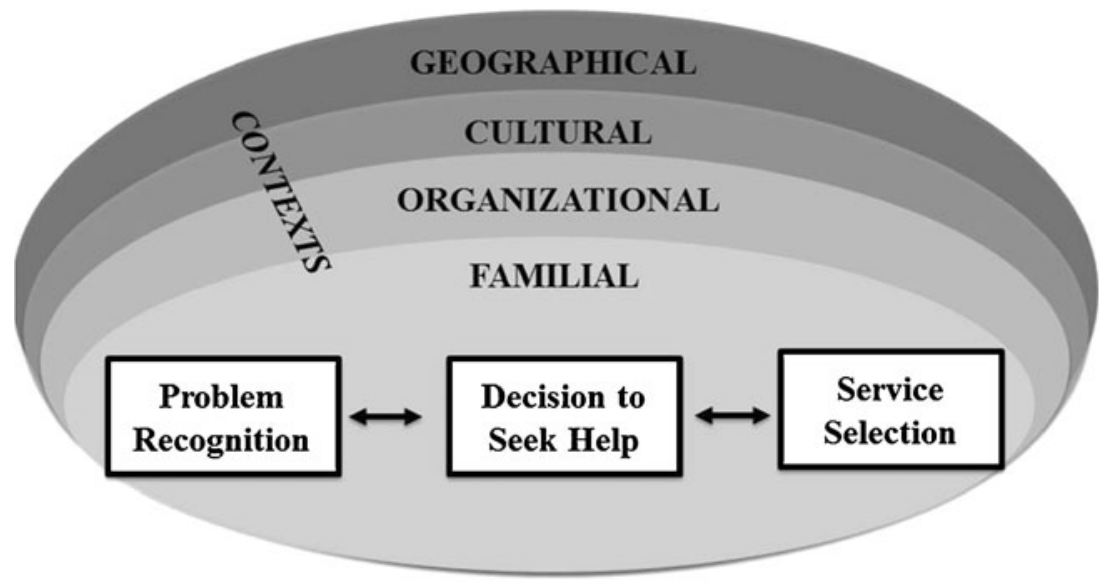

(Cauce et al., 2002)

organizational (e.g., service setting or sector), cultural, and geographical influences on health risks and the help-seeking process that leads to service use. ${ }^{31}$ These environments and the people embedded in them interact to shape how students, parents, teachers, schools, and community members identify health or mental health problems, decide whether to seek help, and select a certain type of service or provider. $^{31}$

\section{Purpose and Unique Contribution}

This study examines whether racial differences in SBHC persist after accounting for student need or health risks. Although SBHCs eliminate important barriers to help seeking such as cost and inconvenience, it is not clear whether school-based services reach the students most in need of care or mitigate other contextual obstacles to service use. Specifically, this study considers whether the prevalence of individual-level health risks, such as depression, suicidality, substance use, sexual activity, and asthma (which are elevated for Black and Latino youth because of their social location), explains differential use of SBHCs by race. In other words, the purpose of our study was to test the proposition that the varied prevalence of health risks by racial group can explain the unique racial patterns of service use in schools observed in recent studies of SBHCs. ${ }^{2,3}$ If racial disparities persist after controlling for health risks, such a finding would suggest that future research is needed to explore the influence of school-specific contexts of help seeking and service use.

This study used ordered logistic regression analyses with school-level controls for the racial composition of the student body to consider the relationship between students' health risks, race, and SBHC service use. In this study, health risks were defined as depressive symptoms and suicidality, use of multiple substances, lifetime sexual activity, and asthma. Student race was used as a proxy for the contextual influences indicated in the socioecological help-seeking theories described above, such as racial bias in referrals and cultural norms that stigmatize help seeking outside of the family. These theories highlight multiple contextual factors, such as family and school culture, that influence adolescents' service use trajectories beyond epidemiologically defined 
health need. Therefore, the study hypothesis was that racial disparities in access would be evident after controlling for individual health risks and school-level demographic characteristics.

\section{Methods}

\section{Study population}

This study used local data from the national Youth Risk Behavior Surveillance System (YRBSS) developed by the Center for Disease Control to monitor the prevalence of health risk behaviors that contribute to unintentional injury, violence, mortality, and morbidity among adolescents. ${ }^{32}$ As part of this larger effort, the Youth Risk Behavior Survey (YRBS), an anonymous epidemiological questionnaire, was administered in the spring of 2007 to 3,560 students in randomly selected schools and classrooms in a large and diverse urban school district with 15 comprehensive SBHCs that emphasize prevention and early intervention for behavioral health problems. Participation in the survey was voluntary and the overall response rate was $77 \%$, resulting in a sample of 2,587 youth (see Table 1). This sample was representative for this school district in terms of gender and grade level, but compared to the general high school student population, survey participants were more likely to be Asian and less likely to be Latino or Black.

Due to random sampling of schools for the YRBSS, this dataset does not include all 15 SBHC sites in this district. Only nine schools with a SBHC were included in the sample; these sites and survey respondents $(n=1,755)$ are the focus of this study. Compared to students in schools without a SBHC, youth at schools with a SBHC were significantly more likely to live with both parents, report higher grades in the past year, and be Latino, but they were significantly less likely to be Black, use multiple substances, or have ever had sexual intercourse (see Table 1). Native American $(n=8)$, Pacific Islander $(n=17)$, and students who declined to state their racial identity $(n=30)$ were also dropped from the analysis because of their small numbers, and the centrality of student race to our analysis (students who were Native American or Pacific Islander and identified with another racial group were coded as Multiracial and were included in the analysis). This resulted in a final sample of 1,700 students that was $50 \%$ male, $17 \%$ Latino, $7 \%$ Black, $59 \%$ Asian, $9 \%$ White, and $4 \%$ Multiracial (see Table 2). Thirty percent of the sample reported sexual activity in their lifetime; $36 \%$ reported symptoms of depression or suicidality in the past 12 months; $62 \%$ had used marijuana, alcohol, or cigarettes in their lifetime; and $25 \%$ had asthma. Forty percent of the sample reported visiting their SBHC at least once in the past year, which is consistent with the administrative data reported by the SBHCs.

\section{Measures}

\section{Independent variables}

Student race The following item from the YRBS was used to classify student race: "What is your race? (Mark All That Apply.)." Responses included American Indian or Alaska Native, Native Hawaiian or Other Pacific Islander, Asian or Asian-American, Black or African-American (non-Hispanic), Hispanic or Latino/Latina, and White. For the purposes of this study, each racial category was recoded into dummy variables. The Multiracial dummy variable included students who marked multiple racial categories. Asian youth were chosen as the reference group because they are the modal racial group in this school district and are uniquely underrepresented in SBHCs.

Health risks Health risks were modeled after previous analyses of the YRBS and included lifetime alcohol, tobacco, and/or marijuana use; depression and suicidality in the past year; asthma; and lifetime sexual activity. ${ }^{33}$ These risk behaviors are consistent with SBHC target areas and are widely used in the empirical literature on adolescent risk factors for negative health and developmental outcomes. ${ }^{2,34}$ 
Table 1

Descriptive characteristics of YRBSS sample (percents)

\begin{tabular}{|c|c|c|c|}
\hline & $\begin{array}{l}\text { All students } \\
(n=\mathbf{2 , 6 0 7 )}\end{array}$ & $\begin{array}{l}\text { Students at schools } \\
\text { without a SBHC } \\
(n=852)\end{array}$ & $\begin{array}{c}\text { Students at schools } \\
\text { with a SBHC } \\
(n=1,755)\end{array}$ \\
\hline \multicolumn{4}{|l|}{ Covariates } \\
\hline Gender (male) & 50.9 & 52.8 & 50.0 \\
\hline Lives with both parents*** & 67.6 & 61.8 & 70.4 \\
\hline \multicolumn{4}{|l|}{ Grade level*** } \\
\hline 9th & 24.6 & 17.7 & 27.9 \\
\hline 10th & 25.0 & 29.7 & 22.8 \\
\hline 11th & 22.8 & 25.4 & 21.6 \\
\hline 12 th & 27.6 & 27.2 & 27.8 \\
\hline Took survey in English & 94.8 & 94.9 & 94.8 \\
\hline \multicolumn{4}{|l|}{ Grades in the past year*** } \\
\hline Mostly A's & 30.4 & 27.5 & 31.7 \\
\hline Mostly B's & 37.0 & 33.3 & 38.8 \\
\hline Mostly C's & 23.2 & 27.8 & 21.0 \\
\hline Mostly D's & 5.9 & 6.7 & 5.5 \\
\hline Mostly F's & 3.5 & 4.7 & 2.9 \\
\hline \multicolumn{4}{|l|}{ Health risks } \\
\hline Ever had sexual intercourse ${ }^{* * *}$ & 34.2 & 40.9 & 30.9 \\
\hline $\begin{array}{l}\text { Depressive and/or suicidal } \\
\text { symptoms in the past } \\
12 \text { months }\end{array}$ & 35.5 & 34.5 & 36.0 \\
\hline \multicolumn{4}{|l|}{ Lifetime substance use ${ }^{* *}$} \\
\hline No substances & 36.6 & 33.5 & 38.1 \\
\hline 1 substance & 28.6 & 26.8 & 29.5 \\
\hline 2 substances & 17.4 & 19.9 & 16.3 \\
\hline 3 substances & 17.4 & 19.9 & 16.2 \\
\hline Diagnosed with asthma & 24.9 & 24.6 & 25.0 \\
\hline \multicolumn{4}{|l|}{ Race (ref group=Asian) } \\
\hline Black*** & 6.6 & 9.0 & 5.4 \\
\hline Latino $* *$ & 15.6 & 12.6 & 17.1 \\
\hline Asian & 55.2 & 55.6 & 54.9 \\
\hline White & 8.0 & 7.0 & 8.5 \\
\hline Other & 1.5 & 1.8 & 1.4 \\
\hline Multiracial & 11.2 & 11.6 & 10.9 \\
\hline Declined to state & 1.9 & 2.4 & 1.7 \\
\hline
\end{tabular}

$* * p<.01 ; * * * p<.001$

The following items from the YRBS were used to assess these risk factors: "Have you ever had sexual intercourse?" Responses included yes and no. "During the past 12 months did you ever feel so sad or hopeless almost every day for two weeks or more in a row that you stopped doing some usual activities?" or "During the past 12 months, did you ever seriously consider attempting suicide?" Responses for each question included yes and no. In this study, a dichotomous variable for depressive and/or suicidal symptoms was created to capture whether a student responded yes to one or both of these questions. "Have you ever 
Table 2

Descriptive characteristics of sample at sites with SBHC (percent or mean)

\begin{tabular}{|c|c|c|c|}
\hline & $\begin{array}{l}\text { All students } \\
(n=\mathbf{1 , 7 0 0})\end{array}$ & $\begin{array}{c}\text { Did not use } \\
\text { SBHC services } \\
(n=889)\end{array}$ & $\begin{array}{c}\text { Used SBHC service } \\
\text { at least once } \\
(n=601)\end{array}$ \\
\hline \multicolumn{4}{|l|}{ Covariates } \\
\hline Gender (male) $)^{* * *}$ & 50.3 & 51.2 & 42.7 \\
\hline Lives with both parents*** & 70.6 & 76.5 & 61.3 \\
\hline \multicolumn{4}{|l|}{ Grade level $* * *$} \\
\hline 9th & 27.7 & 31.2 & 21.8 \\
\hline 10th & 22.8 & 21.7 & 23.3 \\
\hline 11 th & 21.8 & 20.5 & 23.3 \\
\hline 12 th & 27.6 & 26.6 & 31.5 \\
\hline Took survey in English*** & 94.7 & 95.9 & 98.8 \\
\hline \multicolumn{4}{|l|}{ Grades in the past year*** } \\
\hline Mostly A's & 32.0 & 37.7 & 23.8 \\
\hline Mostly B's & 38.7 & 41.8 & 35.7 \\
\hline Mostly C's & 20.9 & 15.7 & 27.6 \\
\hline Mostly D's & 5.5 & 3.2 & 9.0 \\
\hline Mostly F's & 2.9 & 1.6 & 3.9 \\
\hline \multicolumn{4}{|l|}{ Health risks } \\
\hline Ever had sexual intercourse ${ }^{* * *}$ & 30.6 & 21.2 & 45.5 \\
\hline $\begin{array}{l}\text { Depressive and/or } \\
\text { suicidal symptoms*** }\end{array}$ & 35.9 & 30.0 & 44.8 \\
\hline \multicolumn{4}{|l|}{ Substance use $\mathrm{u}^{* * *}$} \\
\hline No substances & 38.2 & 45.2 & 25.0 \\
\hline 1 substance & 29.4 & 31.2 & 28.1 \\
\hline 2 substances & 16.3 & 14.6 & 19.1 \\
\hline 3 substances & 16.1 & 9.0 & 27.8 \\
\hline Asthma* & 24.9 & 23.0 & 27.8 \\
\hline \multicolumn{4}{|l|}{ Race (ref group=Asian) } \\
\hline Black $^{* * *}$ & 5.6 & 3.5 & 8.7 \\
\hline Latino*** & 17.7 & 12.0 & 25.1 \\
\hline Asian*** & 56.7 & 66.8 & 42.1 \\
\hline White & 8.8 & 9.0 & 8.5 \\
\hline Multiracial*** & 11.3 & 8.7 & 15.6 \\
\hline \multicolumn{4}{|l|}{ School context } \\
\hline $\begin{array}{l}\text { Mean } \% \text { of student body that } \\
\text { is Black*** }\end{array}$ & 11.6 & 11.2 & 12.1 \\
\hline $\begin{array}{l}\text { Mean } \% \text { of student body that } \\
\text { is Latino*** }\end{array}$ & 24.6 & 22.0 & 27.9 \\
\hline
\end{tabular}

Native American, Pacific Islander, and students who declined to state their race were dropped from the sample $(n=55)$

$* * * p<.001$

tried cigarette smoking, even one or two puffs?," "During your life, on how many days have you had at least one drink of alcohol?," and "During your life, how many times have you used marijuana?" Responses 
included zero time, one time, two times, three times, four to six times, or seven or more times. For this study, the substance use variable was coded as the sum of the number of substances (alcohol, tobacco, marijuana) the student reported using one or more times. "Has a doctor or nurse ever told you that you have asthma?" Responses included yes or no.

\section{Covariates}

The following items from the YRBS were used to classify student gender, family structure, grade level, grades, and preference for the English language: "What grade are you?" Responses included 9th grade, 10th grade, 11th grade, and 12th grade. "What is your sex?" Responses included male or female. "What best describes where you live?" Responses included a home with both parents, a home with only one parent, other relative's home, a home with more than one family, friend's home, foster home, group care, or waiting placement, hotel or motel, migrant housing, shelter, on the street (no fixed housing), car or van, campground or abandoned building, other transitional or temporary housing, or other living arrangements. For this study, the family structure variable was recoded into a dichotomous form, indicating whether a student lived in a home with both parents or not. "During the past 12 months, how would you describe the grades you mostly received in school?" Responses included, A's and B's, mostly B's, B's and C's, mostly C's, C's and D's, mostly D's, and mostly F's. Finally, all students who took the survey in a language other than English were coded as not preferring English.

These covariates were selected based on previous research demonstrating that boys and students with limited English proficiency are less likely to access SBHCs, whereas poor academic outcomes are positively associated with school-based service use. ${ }^{2}$ Grade level was included because as students move through high school, their familiarity with, or awareness of, their SBHC increases and knowledge of services has been documented as an important factor in help seeking. ${ }^{24,28}$ A variable for living with both parents was also included as a control because a dual-parent household is a proxy for childhood socioeconomic stability and is also a protective factor against adolescent problem behavior and depressed mood. ${ }^{34}$

\section{Dependent variable}

To assess participation in SBHC services, this district added a question to the YRBS, which reads "During the past school year, how often have you visited your school's [health center] for information or services?" Responses included never, one or two times, three to four times, and five or more times.

\section{Analytic Strategy}

A series of ordered logistic regression models with clustered robust standard errors, which account for the nested nature of the dataset (students within schools), were employed using Stata software to estimate the relationships between health risks, student race, and SBHC use. Model 1 includes only individual student covariates and health risks. In model 2 , student race was added, and finally, in model 3, school-level variables for the racial composition of each school were included as control variables. Sensitivity analyses were also conducted to test whether different measurements or analytic approaches lead to different results. Results were similar using multilevel modeling techniques, when the dependent variable was constructed differently (as a dichotomous measure of service use) or when health risks were collapsed into a cumulative measure instead of separate indicators.

\section{Results}

As can be seen in Table 3, all student-level covariates were significantly associated with students' access of SBHCs in model 1. Boys (OR .60, $p<.001)$ and youth living with both parents (OR .61, 


\section{Table 3}

Adjusted odds ratios from ordered logistic regression models predicting number of visits (never, one to two visits, three to four visits, five or more visits) to school-based health center

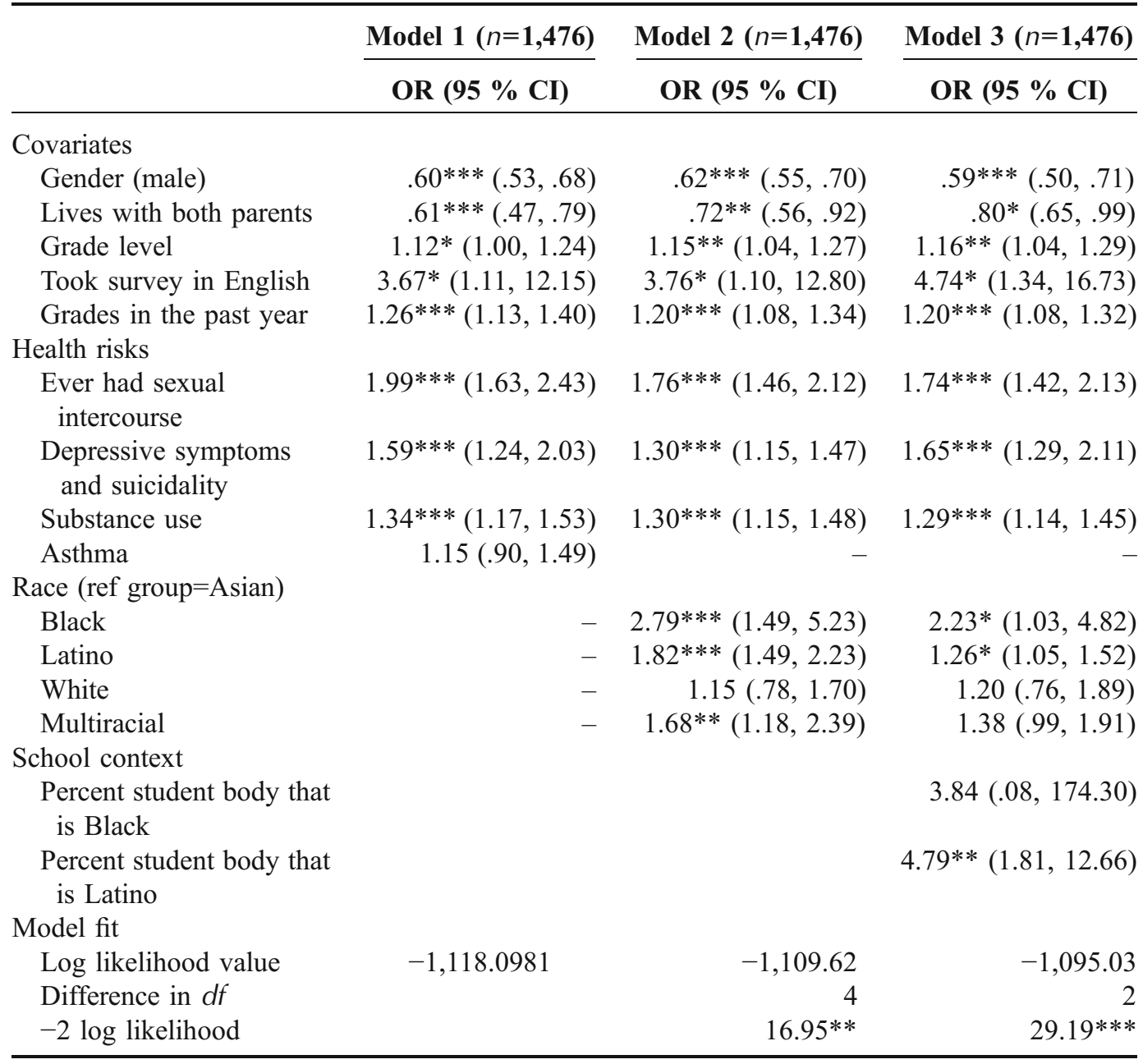

$* p<.05 ; * * p<.01 ; * * * p<.001$

$p<.0001$ ) had significantly lower odds of using school-based services, whereas students in higher grade levels (OR 1.12, $p<.05$ ), with lower academic achievement (OR 1.26, $<<.001$ ), and those who took the survey in English (OR 3.67, $p<.05$ ) all had significantly higher odds of accessing their SBHC. In this base model, students reporting higher health risks had significantly greater odds of using their SBHC. Controlling for gender, family structure, English language preference, grade level, and grade point average, youth had higher odds of using SBHC services more often if they reported ever having sexual intercourse (OR 1.99, $p<.001$ ), depressive symptoms, or suicidality in the past 12 months (OR 1.59, $p<.001$ ) or use of multiple substances in their lifetime (OR 1.34, $p<.001$ ). An asthma diagnosis did not significantly increase students' odds of using services, so this variable was dropped from subsequent models.

After adding student race to the model (model 2), a comparison of the fit statistics between model 1 and model 2 using the likelihood ratio test revealed that model 2 fit the data significantly better than model 1 (difference in $-2 \log$ likelihood, 16.95; difference in $d f=4, p<.01$ ). The odds of 
accessing services among students who had ever had sexual intercourse reduced from 1.99 to 1.76 , as did the odds of service use among youth with depressive symptoms or suicidality, from 1.59 to 1.30 , indicating that the relationship between these health risks and service utilization is likely confounded by unmeasured factors related to students' racial background (e.g., bias in referrals, cultural norms against help seeking, or unmeasured health risks such as trauma). In other words, the lower odds of using services among students who have engaged in sexual activity or experienced depressive symptoms in model 2 may partly be attributed to factors related to student race. The odds of SBHC access did not change for students who reported using substances from model 1 to model 2. Accounting for gender, grade level, family structure, grades, English language preference, and health risks, Black (OR 2.79, $p<.001$ ), Latino (OR 1.82, $p<.001$ ), and Multiracial (OR 1.68, $p<.01$ ) youth had significantly higher odds of using their SBHC compared to Asian students.

To strengthen confidence that the higher odds of service use among Black, Latino, and Multiracial youth were not simply a reflection of the racial composition of their school sites, in model 3, schoollevel variables were added that controlled for the proportion of the student body that was Black or Latino (the school district does not collect data on Multiracial youth in a comparable fashion to the YRBS). The comparison of model 3 to model 2 showed that model 3 fit the data significantly better than model 2 (difference in $-2 \log$ likelihood, 29.19; difference in $d f=2, p<.001$ ). Adding these school contextual variables to the model reduced the odds of Black (OR 2.23, $p<.05$ ), Latino (OR 1.26, $p<.05$ ), and Multiracial (OR 1.38, $p<.10$ ) accessing services, but Black and Latino youth were still significantly more likely than Asian youth to use SBHCs, and to use them more often. This suggests that the relationship between student race and service use is partially attributable to the racial composition of their school. In model 3, after accounting for gender, grade level, family structure, grades, English language preference, health risks, and student race, students attending schools with a higher proportion of Latino students had significantly higher odds of using more SBHC services $(\mathrm{OR} 4.79, p<.01)$.

\section{Limitations}

Findings from this study are only generalizable to other comprehensive school-based health centers service programs that are similarly designed, serving a comparable population of students in an urban setting. Given the limited number of schools participating in this study, the results presented regarding school context must be interpreted with caution. Investigation of these patterns using a larger sample of schools and districts, with measures of multiple contextual influences, in particular referrals from teachers and school staff and bias in referrals and cultural norms against help seeking, would further knowledge development. Additionally, as with all cross-sectional studies, it was not possible to draw causal connections between the variables of interest. This study was exploratory and only intended to demonstrate that even in the case of school-based health centers, where behavioral health services are free and convenient, disparities may persist.

The type and number of covariates available in the YRBS also limits the validity of the findings. The dichotomous nature of the risk factor variables may have masked more nuanced relationships among constructs. Moreover, the survey did not include several important variables that have empirically and theoretically been linked to the prevalence of health and psychosocial problems among adolescents. For example, family socioeconomic status, exposure to violence or trauma, and the availability and use of services outside of school were not accounted for in these analyses. ${ }^{10-19}$ Without these covariates, it is not possible to conclusively rule out "need" as an explanation for patterns of service use by race.

\section{Implications for Behavioral Health}

Consistent with previous research, behavioral and physical health risk factors were positively associated with SBHC use in this urban educational setting, suggesting that this SBHC initiative 
was responsive to the needs of many adolescents who experienced depressive symptoms, used substances, or engaged in sexual activity. ${ }^{2}$ Surprisingly, students who had been diagnosed with asthma were not more likely to access their SBHC. This may reflect the behavioral health orientation of this initiative, which is focused on health promotion, harm reduction, and mental health services, not medical care. As predicted, racial disparities in access were observed after controlling for health risks and other demographic covariates. In particular, Asian students were significantly less likely than Black and Latino youth to access their SBHC. Yet, there is little evidence that Asian youths' needs, particularly their behavioral health concerns, are being met by other systems of care. ${ }^{24}$ Taken together, these findings suggest that there are significant service utilization disparities among Asian youth in urban SBHCs. Although Asian youth generally experience lower levels of health risks than their Black and Latino peers, these results suggest that cultural or contextual factors related to student race may influence service use above and beyond individual health risks. ${ }^{33,36}$

Such disparities may be a result of stronger cultural norms against help seeking among Asian students, lack of culturally or linguistically responsive programming, or limitations in the outreach and referral systems employed by these SBHCs. Referrals from school staff are one of the most common mechanisms through which students enroll in SBHC services in this district. In a program evaluation survey conducted by the SBHC initiative that is the focus of this study, $85 \%$ of service users reported being referred to services and identified teachers as the most common referral source (49\%), followed by a friend (29\%) or SBHC staff member $(18 \%)$. Thus, this study's findings suggest that the needs of Asian students may be overlooked by adults in the school community, perhaps due to the strength of the "model minority" myth in educational settings and the reality that these youth tend to experience lower risks factors than other youth of color. ${ }^{33,36}$

While data presented here consisted of a large proportion of Asian students in an urban school district, which is not representative of many other locales, the findings may still be applicable to educational settings with fewer Asian youth. Other studies of SBHCs serving schools with vastly different racial compositions indicate that Asian youth are consistently underrepresented in SBHCs and Black students tend to be overrepresented, relative to their population in the general student body. ${ }^{2,3}$ Moreover, cultural misunderstandings and stereotypes can be more influential in areas that are not predominantly Asian. ${ }^{35}$ Therefore, school-based health care systems, both with and without high proportions of Asian students, need to assess and tailor outreach, enrollment, and service strategies to address the unique help-seeking preferences of, and barriers faced by, Asian students. Educating school staff members about how to identify health risks among Asian students, increasing culturally specific programming, and improving SBHC providers' Asian language capacity could be important steps in addressing the problem. ${ }^{36}$

Moreover, the findings of this study suggest that the overrepresentation of Black and Latino youth in SBHCs cannot be explained by individual behavioral or physical health risk factors. It is possible that these patterns reflect increased efforts to connect Black and Latino students to additional support in the face of school-related challenges such as culturally unresponsive pedagogy, discrimination in disciplinary practices, and low teacher expectations. ${ }^{37}$ That is, teachers may be making extra efforts to refer Black and Latino students in order to ameliorate some of the educational and interpersonal bias these students have historically experienced in school and under-referring Asian students who are suffering due to "model minority" stereotypes. ${ }^{38}$ Additional research is needed to understand the unique contexts of schools as settings for health and behavioral health service provision and the specific mechanisms that contribute to racial disparities, but teacher-student interactions and referral practices will likely be key factors.

Documenting racial disparities in SBHC utilization is an important first step toward improving policy and services in school-based health-care systems for youth of color. Future research could expand on the present study using longitudinal analyses, additional measures such as exposure to trauma, service use outside of school, contextual influences such as cultural norms or family belief 
systems regarding help seeking, and teacher referral practices. Still, this study suggests that SBHCs present a promising bridge over the behavioral health service-system gap observed for Black and Latino youth. Understanding the mechanisms underlying the utilization patterns described in this study and improving access and services for Asian youth is a critical next step.

\section{Conflict of interest The authors have no conflicts of interest to report.}

\section{References}

1. Brindis CD, Klein J, Schlitt J, et al. School-based health centers: Accessibility and accountability. Journal of Adolescent Health. 2003;32:98-107.

2. Amaral G, Geierstanger S, Soleimanpour S, et al. Mental health characteristics and health-seeking behaviors of adolescent school-based health center users and nonusers. Journal of School Health. 2011; 81:138-145.

3. Walker SC, Kerns SEU, Lyon AR, et al. Impact of school-based health center use on academic outcomes. Journal of Adolescent Health. 2010;46:251-257.

4. Leventhal T, Brooks-Gunn J. The neighborhoods they live in: The effects of neighborhood residence on child and adolescent outcomes. Psychological Bulletin. 2000;126(2):309-337.

5. Pascoe EA, Smart Richman L. Perceived discrimination and health: A meta-analytic review. Psychological Bulletin. 2009;135(4):531-554

6. Williams DR, Neighbors HW, Jackson JS. Racial/ethnic discrimination and health: findings from community studies. American Journal of Public Health. 2003;93:200-208.

7. Sanders-Phillips K, Settles-Reaves B, Walker D, et al. Social inequality and racial discrimination: Risk factors for health disparities in children of color. Pediatrics. 2009;124(3):S176-S186.

8. Slade EP. The relationship between school characteristics and the availability of mental health and related health services in middle and high schools in the United States. The Journal of Behavioral Health Services and Research. 2003;30(4):382-392.

9. Sturm R, Ringel J, Andreyeva T. Geographic disparities in children's mental health care. Pediatrics. 2003;111(4):308-315.

10. Glied S, Hoven CW, Moore RE, et al. Children's access to mental health care: Does insurance matter? Health Affairs. 1997;16(1):167-174.

11. Burns BJ, Costello EJ, Erkanli A, et al. Insurance coverage and mental health service use by adolescents with serious emotional disturbance. Journal of Child and Family Studies. 1997;6(1):89-111.

12. Burns BJ, Costello EJ, Angold A, et al. DataWatch: Children's mental health service use across service sectors. Health Affairs. 1995;14:147-159.

13. Zimmerman FJ. Social and economic determinants of disparities in professional help-seeking for child mental health problems: Evidence from a national sample. Health Services Research 2005;40(5):1514-1533.

14. Wu P, Hoven CW, Bird HR, et al. Depressive and disruptive disorders and mental health service utilization in children and adolescents. Journal of the American Academy of Child \& Adolescent Psychiatry. 1999;38:1081-1090.

15. Elster A, Jarosik J, VanGeest J, et al. Racial and ethnic disparities in health care for adolescents: A systematic review of the literature. Archives of Pediatrics and Adolescent Medicine. 2003;154:867-874.

16. Bui K, Takeuchi D. Ethnic minority adolescents and the use of community mental health care services. American Journal of Community Psychology. 1992;20:403-417.

17. McCabe K, Yeh M, Hough RL, et al. Racial/ethnic variation across five public systems of care for youth. Journal of Emotional and Behavioral Disorders. 1999;7:72-82.

18. Cuffe SP, Waller JL, Addy CL, et al. A longitudinal study of adolescent mental health service use. Journal of Behavioral Health Services \& Research. 2001;28:1-11.

19. Kataoka SH, Zhang L, Wells KB. Unmet need for mental health care among U.S. children: Variation by ethnicity and insurance status. The American Journal of Psychiatry. 2002;159(9):1548-1555.

20. Goldston DB, Molock SD, Whitbeck LB, et al. Cultural considerations in adolescent suicide prevention and psychosocial treatment. American Psychologist. 01 2008;63(1):14-31.

21. Priest N, Paradies Y, Trenerry B, et al. A systematic review of studies examining the relationship between reported racism and health and wellbeing for children and young people. Social Science and Medicine. 2013.

22. Garland AF, Lau AS, Yeh M, et al. Racial and ethnic differences in utilization of mental health services among high-risk youths. American Journal of Psychiatry. Jul 2005;162(7):1336-1336.

23. Shea M, Yeh CJ. Asian American students' cultural values, stigma, and relational self-construal: correlates of attitudes toward professional help seeking. Journal of Mental Health Counseling. 2008;30(2):157-172.

24. Kuhl J, Jarkon-Horlick L, Morrissey RF. Measuring barriers to help-seeking behavior in adolescents. Journal of Youth and Adolescence. 1997;26(6):637-650.

25. Brener ND, Weist M, Adelman HS, et al. Mental health and social services: Results from the School Health Policies and Programs Study 2006. Journal of School Health. 2007;77:486-499.

26. Morris EW. 'Tuck in that shirt!' Race, class, gender and discipline in an urban school. Sociological Perspectives. 2005;48(1):25-48.

27. Neal LV, McCray AD, Webb-Johnson G, et al. The effects of African American movement styles on teachers' perceptions and reactions. Journal of Special Education. 2003;37(1):49-57.

28. Srebnik D, Cauce AM, Baydar N. Help-seeking pathways for children and adolescents. Journal of Emotional and Behavioral Disorders. 1996;4(4):210-220. 
29. Lau AS, Garland AF, Yeh M, et al. Race/ethnicity and inter-informant agreement in assessing adolescent psychopathology. Journal of Emotional \& Behavioral Disorders. 2004;12:145-156.

30. Yeh M, McCabe K, Hurlburt M, et al. Referral sources, diagnoses, and service types of youth in public outpatient mental health care: A focus on ethnic minorities. Journal of Behavioral Health Services \& Research. 2002;29(1):45-60.

31. Cauce AM, Domenech-Rodriguez M, Paradise M, et al. Cultural and contextual influences in mental health help seeking: A focus on ethnic minority youth. Journal of Counseling and Clinical Psychology. 2002;70(1):44-55.

32. Eaton DK, Kann L, Kinchen S, et al. Youth risk behavior surveillance-United States, 2007. MMWR Surveillance Summary. 2008;57(4):1-131.

33. Grunbaum J, Lowry, R., Kann, L., et al. Prevalence of health risk behaviors among Asian American/Pacific Islander high school students. Journal of Adolescent Health. 2000;27:322-330.

34. Costello DM, Swendsen J, Rose JS, et al. Risk and protective factors associated with trajectories of depressed mood From adolescence to early adulthood. Journal of Consulting and Clinical Psychology. 2008;76(2):173-183.

35. Lin AC, Harris D. The colors of poverty. New York: Russell Sage; 2008:331.

36. Anyon Y, Whitaker K, Shields J, et al. Help-seeking in the school context: Understanding Chinese American adolescents' underutilization of school health services. Journal of School Health. in press.

37. Deschenes S, Cuban L, Tyack D. Mismatch: Historical perspectives on schools and students who don't fit them. Teachers College Record. 2001;103(4):525-547.

38. Chang D, Sue S. The effects of race and problem type on teachers' assessments of student behavior. Journal of Counseling and Clinical Psychology. 2003;71(2):235-242. 